\title{
Breast Feeding: - Blessing for Mother and Child
}

\author{
Latefa Hamdan Almansoori and Asiya Nazir* \\ College of Arts and Sciences, Abu Dhabi University, Abu Dhabi,United Arab Emirates
}

*Corresponding author: Asiya Nazir, College of Arts and Sciences, Abu Dhabi University, Abu Dhabi United Arab Emirates

\begin{tabular}{|c|c|}
\hline ARTICLE INFO & ABSTRACT \\
\hline Received: 幽 July 17, 2020 & Breastfeeding is a practice that can ensure nutrients and help in infant growth and \\
\hline Published: 㓞 August 06, 2020 & $\begin{array}{l}\text { development. Moreover, breastfeeding is proven to reduce infant mortality, prevents } \\
\text { child from diseases and benefits the mother as well. }\end{array}$ \\
\hline
\end{tabular}

Citation: Latefa Hamdan Almansoori, Asiya Nazir. Breast Feeding: - Blessing for Mother and Child. Biomed J Sci \& Tech Res 29(2)-2020. BJSTR. MS.ID.004787.

Keywords: Breastfeeding; Infant Mortality; Human Milk

\section{Introduction}

Breastfeeding and human milk are the significant components of the infant's nutrition. Since there are various medical and neurodevelopmental benefits of breastfeeding, infants' nutrition has to be discussed as a public health issue instead of a lifestyle choice [1]. Children should receive breast milk throughout the first year of life or even longer. Therefore, since breastfeeding has benefits for both women and children, it should be considered a medical indication rather than a separate option for feeding.

\section{Benefits for Children}

According to [2], one of the main advantages of breast milk is that it has multiple components that have a positive impact on child's health. Moreover, as the child grows, the components of the milk change according to one's needs. As a result, breastfeeding mothers protect their children from various diseases such as anemia, calcium deficiency, iodine, and frequent severe infectious diseases. The primary biologically active components of breast milk are immunoglobulins, lysozyme, lactoferrin, and leukocytes [3]. With the help of these components, the baby becomes protected from infections. Another advantage of breast milk is that as the child gets older, the concentration of immunoglobulins in milk increases [4]. This leads to the fact that older children maintain strong immune support with mother's milk. According to Gunderson et al.longterm feeding helps to decrease child's risk of getting diabetes. What is more, breast milk reduces risk of maintaining atherosclerosis and other diseases.
When it comes to another component of mother's milkoligosaccharides, it protects a child from allergies with the help of development of its microflora [5]. It is also important to state that breast milk contains proteins. This component helps to promote the development of the child's brain. What is more, milk from the mother's breast forms a protective film on the child's teeth [6]. As a result, biologically active substances protect children's teeth from harmful microorganisms and do not let them multiply in the oral cavity. That is why those children that consume breast milk are less prone to caries [7]. With the growth of a child, milk in the breast changes too. During the second year of lactation, milk becomes fatter, and the number of antibodies in it increases. As a result, breastfeeding provides natural protection from infections. Feeding after a year also contributes to the more natural formation of speech. Therefore, breast milk has a significant amount of ingredients that protect a child from various diseases and lead to one's faster development.

\section{Benefits for Mother}

It is essential to mention that the physical state of the mother after childbirth is weak. Nevertheless, breastfeeding helps a woman to get over it. When the baby eats breast milk, the uterus of the mother shrinks. That is why it decreases faster in those mothers who feed their children with breast milk, than in those who do not. Another significant factor is that during breastfeeding, mother and a child establish close psychological contact. This is 
also why infants are sensitive to the mother's mental state. During the period of lactation, a women's body produces special hormones that cause feelings of satisfaction, reduce anxiety and give rest. As a result, breastfeeding mothers have the mental strength to overcome problems that occur after the birth of a child. Moreover, these hormones help to go through insomnia.Another benefit that a mother gets with breastfeeding is that such women are less likely to experience postpartum depression. As stated below, lactation helps to produce specific hormones that increase the feeling of satisfaction.

What is more, mothers who feed their children with breast milk have a lower risk of developing diabetes by $4-12 \%$ for each year of breastfeeding [8]. However, if the disease is already developed, breastfeeding has no effect. Women who continue to breastfeed for 12-23 months are significantly less likely to suffer from cardiovascular diseases. A vital factor is that the researchers prove that lactation helps to decrease the risk of breast and ovarian cancer. On average, each year of breastfeeding reduces the risk of breast cancer by $4.3 \%$ [9]. Nevertheless, it is vital to remember that lactation is a very individual process that cannot be predicted [10]. That is why if a woman has no or little milk, one should understand that there are many criteria that affect this.

\section{Premature Infants}

Breastfeeding has a great importance for premature children. It has a significant health-improving effect on such babies. Among breastfed infants in this category, the number of hospitalizations due to digestive and respiratory problems is significantly reduced [11]. What is more, premature children that receive breast milk are noticed to have better state and the length of their stay in the intensive care unit is reduced. That is why premature children must receive breast milk. There are also options, such as donor milk, which can be stored for 96 hours at a proper temperature.

ISSN: 2574-1241

DOI: $10.26717 /$ BJSTR.2020.29.004787

Asiya Nazir. Biomed J Sci \& Tech Res

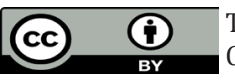

This work is licensed under Creative Commons Attribution 4.0 License

Submission Link: https://biomedres.us/submit-manuscript.php

\section{Conclusion}

All in all, various studies prove the benefits of breastfeeding both for the child and the mother; that is why each woman should practice it. Moreover, if a woman refuses to breastfeed, it might negatively affect the child's health. Therefore, breastfeeding should be considered as a medical indication, not a separate option for the mother and baby.

\section{References}

1. (2012) Breastfeeding and the Use of Human Milk.

2. Breastfeeding Overview. (n.d.). World Health Organization.

3. (1970) The physiological basis of breastfeeding.

4. Walker WA, Iyengar RS (2015) Breast milk, microbiota, and intestinal immune homeostasis. Pediatric research 77(1-2): 220-228.

5. Hegar B, Wibowo Y, Basrowi RW, RanuhRG, Sudarmo SM, et al. (2019) The role of two human milk oligosaccharides, 2-fucosyllactose and lacto-N-neotetraose, in infant nutrition. Pediatric gastroenterology, hepatology \& nutrition 22(4): 330-340.

6. Salone LR, Vann WF, Dee DL (2013) Breastfeeding: an overview of oral and general health benefits. The Journal of the American Dental Association 144(2): 143-151.

7. Nirunsittirat A, Pitiphat W, McKinney M, DeRouen TA, Chansamak N, et al. (2016) Breastfeeding duration and childhood caries: a cohort study. Caries research 50(5): 498-507.

8. Aune D, Norat T, Romundstad P, Vatten LJ (2014) Breastfeeding and the maternal risk of type 2 diabetes: A systematic review and doseresponse meta-analysis of cohort studies. Nutrition, Metabolism and Cardiovascular Diseases 24(2): 107-115.

9. De Silva M, Senarath U, Gunatilake M, Lokuhetty D (2010) Prolonged breastfeeding reduces risk of breast cancer in Sri Lankan women: A case-control study. Cancer epidemiology 34(3): 267-273.

10. Thulier D, Mercer J (2009) Variables associated with breastfeeding duration. Journal of Obstetric, Gynecologic \& Neonatal Nursing 38(3): 259-268.

11. Ahmed AH, Sands LP (2010) Effect of pre-and postdischarge interventions on breastfeeding outcomes and weight gain among premature infants. Journal of Obstetric, Gynecologic \& Neonatal Nursing 39(1): 53-63.

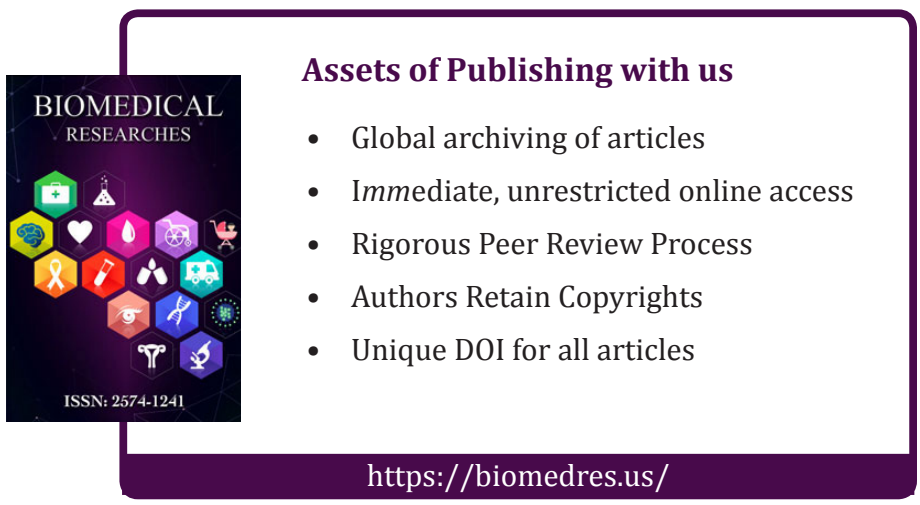

Copyright@ Asiya Nazir | Biomed J Sci \& Tech Res | BJSTR. MS.ID.004787. 